\title{
Violência Doméstica: Reflexões sobre o Agir Profissional
}

Violence against children: reflexions of practice

Mariana Porto

Ruwer de

Azambuja

Pontifícia

Universidade

Católica do Rio

Grande do Sul

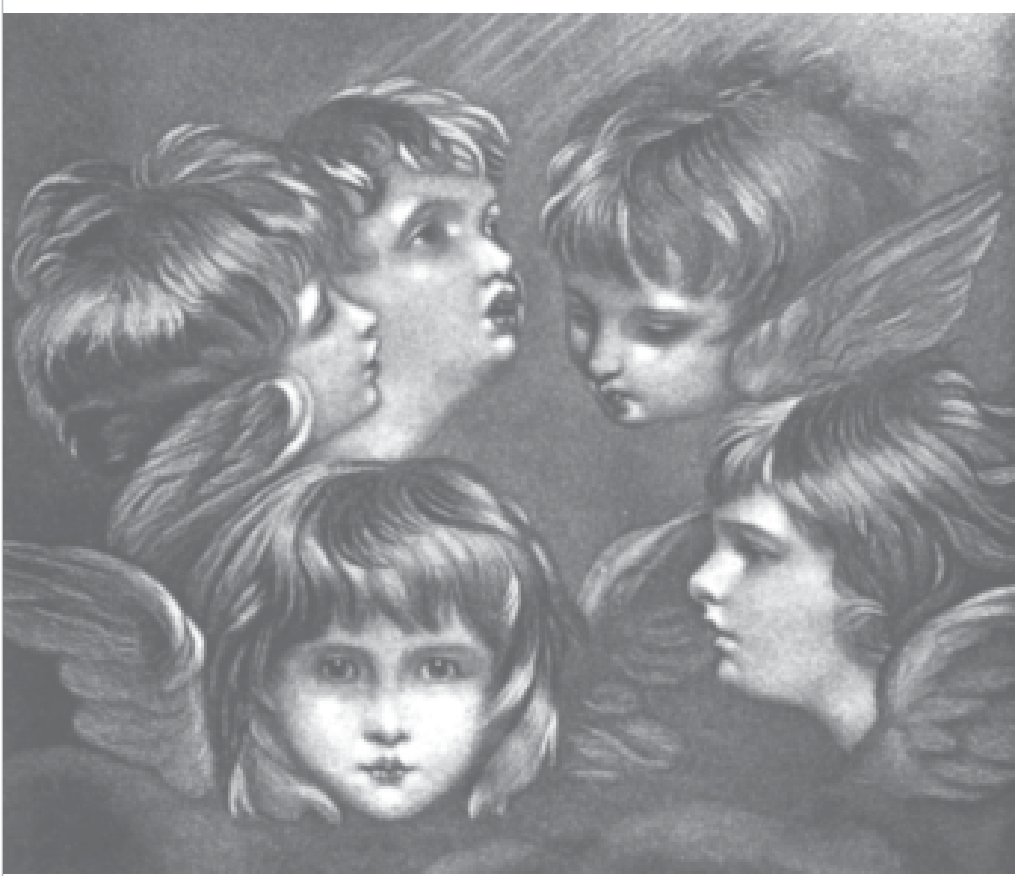




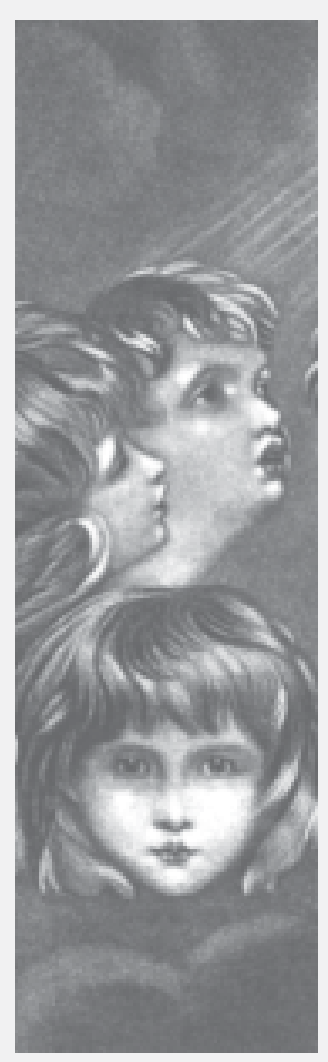

Resumo: A partir da experiência como estagiária de Psicologia Comunitária, a autora discute as dificuldades no manejo dos maus-tratos infantis, em especial do abuso sexual. Apesar de o Estatuto da Criança e do Adolescente prever obrigatoriedade de notificação ao Conselho Tutelar até mesmos dos casos de suspeita, a subnotificação é uma realidade que ocorre como conseqüência do despreparo dos profissionais, da falta de uma estrutura de apoio, do temor de envolvimento com questões legais bem como da atuação nem sempre satisfatória dos conselheiros tutelares. Isso gera um desconhecimento da real dimensão do problema, bem como a impunidade dos agressores.

Palavras Chave: maus-tratos infantis, abuso sexual, manejo profissional.

Abstract:Based on an experience of Community Psychology practice, the author discusses the difficulties of management of child abuse situation and, more specifically, sexual abuse. In spite of the "Child and Adolescent Law" (document in Brazil) determination that any case of child abuse, even if it's only a suspicion, must be notified to authorities, it does not really work. It occurs because professionals are unprepared, it does not exist a framework support and there is fear of legal evolvement. This situation produces ignorance about the real dimension of the problem and no punishment of the aggressors.

Key Words: child abuse, sexual abuse, professional management.

A idéia de realizar um artigo relacionado às dificuldades encontradas por profissionais que lidam com casos de violência contra crianças partiu da experiência como estagiária de Psicologia Comunitária em um posto de saúde de uma vila de Porto Alegre. A prática diária levou à constatação de que muitas crianças têm sua infância e vida marcadas por situações extremamente violentas e traumatizantes. Através de relatos nas entrevistas de triagens e depoimentos nos grupos de convivência, percebia-se que, muitas vezes, as crianças não têm oportunidade de vivenciar sua infância. As mães buscavam o serviço de Psicologia com a queixa de que os filhos são "terríveis, só aprontam e não obedecem..." e, numa tentativa de educálos, impunham-Ihes severos castigos, como demonstra o seguinte depoimento:

"Eu não sei mais o que fazer com esse guri, até já pensei em colocar ele num colégio desses de internato. Ele não me obedece, eu mando ele ir no armazém e ele fica pela rua, brincando, demora para voltar, fica tomando pinga no armazém, catando toco de cigarro do chão! É uma peste! E eu fico 
em casa, preocupada, pensando que aconteceu alguma coisa de ruim. Porque tu sabe, né, aqui na Vila dá de tudo... mas aí eu dou nele, eu bato, bato, bato, bato para ver se ele aprende. Porque eu não quero que ele fique aí pelas ruas e depois vire marginal. Eu sei que bater é ruim, eu tento conversar, mas ele não me obedece. Eu não sei mais o que fazer..." (Rosa) .

Essa mãe, por incrível que pareça, estava falando de uma criança de apenas quatro anos que, com tão pouca idade, devia ajudá-la nos serviços domésticos e ir ao armazém. Contudo, podemos perceber que existia um temor de que o filho seguisse o mesmo caminho do pai, que havia sido preso recentemente, portanto, as surras representavam uma tentativa equivocada de educação e imposição de limites. Do mesmo modo, assim como essa mãe depositava expectativas inadequadas à pouca idade do filho, muitas outras pessoas também o fazem quotidianamente. Devido às reduzidas condições financeiras e aos poucos recursos sociais disponíveis, muitas vezes é comum que os irmãos mais velhos tomem conta dos menores. Isso ocorre porque os pais precisam trabalhar e não existem vagas suficientes nas creches públicas locais ou condições financeiras para matricular os filhos em escolas particulares. Além disso, muitas pessoas não entendem que as crianças, devido a sua própria condição de imaturidade, agem e devem ser tratadas como tal, não tendo condições de assumir responsabilidades de adultos.

Como um agravante à falta de espaço para a plena vivência da infância nas camadas populares, também existe a dura realidade do abuso sexual. Em diferentes momentos, escutamos mulheres relatando histórias de agressões cometidas por pais, padrastos, namorados, tios... Todas elas carregavam uma marca muito profunda, como um fardo a mais na sua condição de mulher e de submissão. Os depoimentos são dramáticos e expressam o impacto do trauma sofrido:

"Eu era 'estrupada' pelo meu padrasto, eu e minhas irmãs. A minha mãe sabia, mas não podia fazer nada, coitada (...) aí, quando eu tinha uns treze anos, eu resolvi sair de casa e morar com o João. Porque ou eu ficava em casa para ser 'comida' pelo meu padrasto ou eu saía para ser 'comida' pelo meu namorado" (Aparecida).

Nesse depoimento, percebe-se que as agressões podem acabar manifestando-se até mesmo intergeracionalmente. A referência de Aparecida sobre sua mãe como uma "coitada" mostra que esta, mesmo sabendo das agressões sofridas pelas filhas, por diversas razões, não conseguia separar-se do companheiro. Tal dado demonstra a existência de uma relação desigual entre os sexos, sendo que essa mesma condição passou a se repetir no relacionamento da filha. Aparecida havia fugido de casa para escapar do padrasto, mas acabou vivendo uma situação muito semelhante com o companheiro, com quem também mantinha um relacionamento marcado pelas agressões físicas e constantes separações e retornos.

Contudo, também havia casos como o de Sandra que, apesar das vivências traumáticas infantis demonstradas no relato abaixo, conseguira desenvolver-se e estabelecer um relacionamento - aparentemente - saudável com o companheiro. Muito cuidadosa com os filhos, dizia freqüentar o grupo de mulheres para "sair um pouco de casa, se distrair", nunca tendo feito queixas sobre o marido: 
"Quando criança eu era... como é mesmo o nome... masturbada pelo meu pai, ele ficava me passando a mão e colocando o dedo em mim. Tudo isso com uma arma na minha cabeça, a arma tava sempre carregada... credo, eu me lembro da cena até hoje (...) esses tempos até eu fui na casa dele e tinha uma menina lá, de doze anos, filha de uma amiga dele. A mãe vende ela até por 50 centavos! E me contaram que ele pagava para transar com ela. Quando eu ouvi isso me deu uma coisa, comecei a imaginar ela e era como se fosse eu, sabe... me lembrei de tudo que ele fazia..." (Sandra).

Ainda que seja exercida sobretudo como um processo social, a violência também é objeto de investigação da área da saúde, pois esta, além de atender as vítimas, também tem a função de elaborar estratégias de prevenção. Devido ao grande número de atingidos e à magnitude de suas seqüelas, a violência adquiriu um caráter endêmico, convertendo-se em um dos mais graves problemas mundiais de saúde pública. No Brasil, desde a década de 60, o quadro geral de mortalidade revela a transição das doenças infecto-parasitárias para a violência como um fenômeno relevante. A década de 80 representa o principal ponto de transição, quando se registrou um aumento de cerca de 29\% na proporção de mortes violentas, passando a ser essa a segunda causa de óbito, perdendo apenas para as doenças cardiovasculares (Minayo e Souza, 1998).

No campo da saúde, somente a partir dos anos 60 é que se percebeu um real interesse para a questão da violência contra crianças, principalmente por parte da pediatria norteamericana, influenciada pelo movimento feminista, que denunciou as agressões ocorridas dentro dos lares. A partir de casos acompanhados pelo Serviço de Pediatria do Hospital de Denver, Kempe e Silverman criaram, em 1962, a expressão "Síndrome da Criança Espancada”. Essa definição, contudo, relatava apenas o uso da força física na agressão. Mais tarde, esse conceito foi ampliado por Fontana, que mostrou que as crianças também podem ser agredidas emocionalmente. A expressão anterior foi, então, substituída por "Síndrome da Criança Maltratada", incluindo-se a negligência, a omissão e os outros aspectos psicológicos. As investigações mais recentes têm acrescentado situações como as das crianças de fronteiras e da guerra, o maltrato étnico, os rituais satânicos e o sofrimento fetal (Santana-Tavira; Sánchez-Ahedo; Herrera-Basto, 1998).

No entanto, foi somente a partir dos anos 80 que se passou a perceber, realmente, uma modificação na forma de lidar com a infância e a adolescência no Brasil. O momento político de abertura democrática e a constatação da ineficácia do Código de Menores e os projetos daí derivados levou à busca de uma abordagem inovadora. Passou a ocorrer uma "efervescência" em torno do tema, com a explosão de pesquisas, seminários e cursos que culminaram no I Seminário Latino-Americano de Alternativas Comunitárias de Atendimento a Meninos e Meninas de Rua, em 1984, um marco na luta pelos direitos das crianças e adolescentes. Em 1985, foi fundado, em Campinas, o Centro Regional de Atenção aos Maus-tratos na Infância (Crami) e, em 1988, a Associação Brasileira Multiprofissional de Proteção à Infância e à Adolescência (Abrapia), no Rio de Janeiro. Desde então, inúmeras outras associações e serviços de atendimento e assistência a crianças e adolescentes vítimas de maus-tratos foram criados por todo o País (Vogel, 1995; Gonçalves, Ferreira e Marques, 1999).
No campo da saúde, somente a partir dos anos 60 é que se percebeu um real interesse para a questão da violência contra crianças, principalmente por parte da pediatria norteamericana, influenciada pelo movimento feminista, que denunciou as agressões ocorridas dentro dos lares. 
A partir daí, estabeleceu-se uma articulação do Poder Público Federal com a sociedade civil, transformando em preceito constitucional as concepções da Convenção Internacional dos Direitos da Criança. Todo esse processo acabou levando à aprovação da Lei no 8069 - o Estatuto da Criança e do Adolescente, Eca, uma legislação inovadora que substituiu o já ultrapassado Código de Menores. O Eca vê a criança e o adolescente como "cidadãos" e "seres em desenvolvimento" que, dessa forma, são passíveis de direitos e necessitam de proteção integral (Brasil, 1990).

Ainda assim, a realidade das crianças e dos jovens de todo o mundo está longe do que pregam o Eca e a Declaração Universal dos Direitos da Criança. Além da exploração da mão-de-obra infanto-juvenil nos países pobres e em desenvolvimento, em países desenvolvidos, as crianças também são

Além da exploração da mão-de-obra infanto-juvenil nos países pobres e em desenvolvimento, em países desenvolvidos, as crianças também são maltratadas. maltratadas. Nos Estados Unidos, em 1991, foram notificados 2,7 milhões de casos; na Suíça, país conhecido por não se envolver em conflitos bélicos por séculos, um terço dos pais impõe castigos severos a seus filhos, e, apesar de esse ser um problema mundial, ainda se desconhece sua prevalência, visto que os dados existentes são dispersos e representam apenas os casos notificados, permanecendo de fora um imenso contingente sem registro (Santana-Tavira; Sánchez-Ahedo; HerreraBasto, 1998).

Segundo Minayo (2001), a taxa de mortalidade infantil é uma das mais evidentes manifestações da situação em que se encontram as crianças. O Brasil, ainda que tenha apresentado uma significativa redução nos últimos anos, permanece com uma taxa elevada entre os países da América Latina. Em 1996, cerca de $22,6 \%$ das mortes de crianças com até cinco anos de idade deviam-se a causas violentas, aumentando para $48,2 \%$ na faixa etária entre cinco e nove anos, 56\% entre 10 e 14 anos e $72 \%$ entre 15 e 19 anos, ou seja, a população infanto-juvenil brasileira morre mais por conflitos sociais do que por doenças.

Segundo a autora, podemos distinguir, no Brasil, uma violência do tipo estrutural, cujas expressões mais fortes são o trabalho infantil e a existência de crianças vivendo nas ruas e em instituições fechadas; uma violência social, cujas mais vivas manifestações configuram-se na violência doméstica, e uma violência delinqüencial, na qual as crianças são vítimas e atores. A violência estrutural é aquela que incide sobre as condições de vida das pessoas, a partir de decisões históricas, econômicas e sociais que, pelo caráter de perenidade, acaba tendo uma conotação "natural". É o caso do grande número de crianças vivendo na pobreza - em 2000, cerca de 34\% da população entre zero e 17 anos - e sem escolarização - em 1997, a média de anos de estudo de crianças na faixa etária entre sete e 14 anos foi de 3,4 anos. Isso faz, por exemplo, com que a exploração da mãode-obra infantil seja erroneamente justificada como uma forma de as crianças garantirem seu próprio sustento.

No estágio em Psicologia Comunitária, também atendemos casos como o de Leonardo: a escola o encaminhara para atendimento psicológico no posto devido a problemas de aprendizagem (estava repetindo a primeira série pela terceira vez). No decorrer dos atendimentos, ficamos sabendo que ele já havia sido atendido por uma psicóloga voluntária, que havia descoberto que o menino havia sido 
abusado sexualmente por um tio e um primo. Na época, a profissional preferiu trabalhar a problemática com a família, optando, naquele momento, em não efetuar o registro no Conselho Tutelar. Contudo, por dificuldades pessoais da psicóloga, o atendimento teve que ser interrompido. Anos depois, o menino retornou ao posto com a mesma queixa.

Durante a avaliação, constatamos que a avó (Maria), cuidadora do menino, não conseguia lidar adequadamente com a situação sem acompanhamento. O histórico familiar mostrava que as agressões já faziam parte de sua organização, pois tanto a mãe quanto o tio de Leonardo haviam sido abusados sexualmente pelo pai durante a infância. Maria, em seu casamento, não conseguira romper com o ciclo de violência perpetuado pelo marido e, agora, seu filho estava repetindo com o sobrinho o que o pai Ihe havia feito. Quando questionada sobre o assunto, ora dizia que tudo havia sido invenção de Leonardo, ora afirmava que nada mais estava acontecendo porque o filho estava morando em uma casa nos fundos da sua. Contudo, nas entrevistas com Leonardo, os jogos e desenhos sempre eram marcados por um conteúdo altamente sexualizado e agressivo. Além disso, constantemente afirmava que ele e o tio eram "como gato e cão, viviam brigando".

Tais aspectos correspondem ao que tem sido registrado na literatura sobre a dinâmica das famílias de crianças abusadas. Segundo Furniss (1993), quando irmãos mais velhos ou adolescentes abusam de crianças menores, geralmente encontramos um caso em que eles mesmos sofreram ou testemunharam atos de abuso sexual. Provavelmente, o fato de terem crescido em um ambiente no qual o relacionamento adulto-criança é empobrecido emocionalmente e altamente sexualizado faz com que se identifiquem com o agressor.

Através das entrevistas de acompanhamento do caso, concluímos que a avó, responsável pelo menino, não estava "dando conta" do problema. Leonardo apresentava sintomas que Ihe traziam muito sofrimento: não conseguia aprender a ler e a escrever, tinha dificuldades de relacionamento com os colegas e um comportamento desadaptado na escola. Não permanecia sentado, perseguia as meninas tentando beijá-las, usava gestos e palavras obscenas, o que fez com que a professora combinasse com a avó que todos os dias ele sairia logo após o intervalo, pois "ficava muito agitado". Maria, por sua vez, parecia não ver problema nessa situação, não se importando que Leonardo perdesse as aulas e, tampouco, parecia relacionar os fatos com os abusos sofridos por ele.

Dessa forma, a equipe de Psicologia do posto de saúde decidiu que o caso deveria ser encaminhado para o Conselho Tutelar, que ficaria responsável por obter uma vaga em alguma clínica para o atendimento psicoterápico familiar (serviço não disponível no posto), bem como seria responsável pelo acompanhamento do tratamento. Essa não foi, porém, uma decisão fácil, pois nos deparamos com vários questionamentos: como a família reagirá? Será que esse tio não poderá fazer ameaças às profissionais envolvidas? Irá o Conselho Tutelar lidar adequadamente com a situação? (havia indícios de que alguns dos conselheiros não estavam muito preparados). Será mesmo necessário apelar para decisão tão drástica? O que irá acontecer com o menino? Será que nos envolveremos com algum processo judicial? 
Buscando resolver a situação e não nos omitirmos diante dos fatos, resolvemos entrar em contato com os profissionais das outras instituições em que o menino estava inserido (escola e centro de lazer) para fazermos o registro no Conselho Tutelar de modo conjunto. Esperávamos que, com isso, a responsabilidade ficasse diluída entre todos e que a família percebesse a gravidade da situação, aceitando melhor os fatos. Contudo, essa não foi uma tarefa fácil, pois encontramos muitas resistências. Na escola, a professora dizia que não tinha conhecimento da vivência de abuso, pois nem o menino e nem a avó (responsável por ele) haviam falado sobre o assunto. Do mesmo modo, no centro de lazer, "nunca havia aparecido nada". Sem dúvida, esses profissionais também se deparavam com os mesmos questionamentos que nos havíamos feito anteriormente...

Segundo Gonçalves e Ferreira (2002), tais fatos não são incomuns entre profissionais que lidam com casos de abuso sexual. Apesar de o Estatuto da Criança e do Adolescente (Brasil, 1990) prever a obrigatoriedade de notificação e punição para os profissionais que se isentarem diante da confirmação ou mesmo da suspeita de maus tratos contra crianças, a sub-notificação é uma realidade, não só no Brasil, mas em diversos outros países. As principais razões para isso, segundo os autores, podem ser sintetizadas no seguinte:

Falta de preparo profissional - a maioria dos cursos de graduação não fornece informações básicas sobre o diagnóstico e o manejo de casos de maus-tratos;

Sigilo profissional - muitos profissionais se questionam se a notificação seria uma quebra do sigilo profissional (poucos sabem que tanto o Conselho Federal de Psicologia quanto o de Medicina permitem a quebra do sigilo nesses casos);

Transtornos legais - assim como os profissionais americanos, os brasileiros temem os transtornos legais que advêm da notificação (realização de laudos, prestação de depoimentos, comparecimento a audiências, etc.);

Dificuldades do próprio caso - casos que envolvem violência contra criança geralmente se mostram "pesados" e desgastantes para o profissional, pois a família pode não desejar ou dificultar a notificação;

- Questões estruturais - a atuação dos conselhos tutelares, além de não ocorrer em todos os municípios brasileiros, muitas vezes é insatisfatória, pois contam com pouca infra-estrutura, formação heterogênea de conselheiros, grande demanda de serviços e precariedade de serviços de retaguarda para a execução de medidas aplicadas;

- Cultura familiar - em nossa sociedade, a privacidade familiar é um valor de muita força, sendo que qualquer intervenção é tida como intrusiva e ofensiva à autoridade dos pais.

Por fim, a situação só ficou resolvida quando apelamos para o Estatuto da Criança e do Adolescente (Brasil, 1990), que prevê, no artigo 13, a obrigatoriedade da notificação até mesmo dos casos de suspeita de maus tratos, e, no artigo 245, a penalidade de multa para médico, professor ou responsável por estabelecimento de atenção à saúde e de ensino que deixe de comunicar à autoridade competente tais casos. 
Com base na legislação existente, alegamos que tanto os profissionais da escola quanto os do centro de lazer tinham a obrigação de suspeitar que algo errado estava acontecendo com o menino a partir dos sintomas apresentados. Dessa forma, deveriam, obrigatoriamente, notificar as suspeitas ao Conselho Tutelar. Com esse argumento, conseguimos vencer as resistências e todos concordaram que realmente seria mais adequado encaminhar a família ao Conselho Tutelar.

Cabe destacar que a subnotificação dos casos de violência contra crianças é um problema grave, na medida em que é partir de dados epidemiológicos que os governantes pautam as ações sociais de prevenção. Ao se mostrar como uma realidade desconhecida, ou mal conhecida, acaba por se configurar como mais uma forma de violência, que opera no nível estrutural: a invisibilidade (que vem acompanhada pelo descaso).

Estudos realizados sobre a notificação dos casos de violência contra crianças e adolescentes mostram que as fontes oficiais de informação oferecem dados incompletos devido a formulários mal preenchidos. Tal fato possui sérias implicações, tais como a impunidade do agressor e a falta de mobilização social para a mudança. A análise dos boletins de ocorrência policial de violência cometida contra crianças mostra que as informações sobre o agressor, o tipo de evento, a instrução da vítima e local da ocorrência do evento, na maioria das vezes, inexistem ou são incompletos. Uma explicação para esse descaso é a hipótese de que não é importante identificar o agressor ou a vítima, visto que suas vidas valem pouco, pois, na maioria das vezes, as vítimas são pessoas de classe social baixa (Njaine et al,1997).
Em um estudo realizado por Gomes (1998), a análise de dados de 106 ocorrências de violência doméstica contra crianças na faixa entre zero e cinco anos de delegacias do município do Rio de Janeiro, em 1990, mostrou que somente 24 delas viraram inquérito e, dessas, apenas uma tornou-se processo, tendo sido o pretenso agressor absolvido. Dentre os casos estudados, em apenas $31 \%$ das vítimas foram realizados exames para fundamentar a denúncia e $32 \%$ possuíam testemunhas. Esses dados, de certa forma, explicam porque a maioria das denúncias acaba não se transformando em processo devido à falta de provas. Portanto, a má qualidade dos registros de denúncias de eventos violentos contra crianças acaba deixando o agressor impune, o que reflete a falta de empenho dos responsáveis, a banalização e a indiferença da sociedade com a situação das crianças.

Porém, o problema parece estar, ainda, antes do registro de ocorrência pois, conforme já foi demonstrado pelos casos apresentados, muitos profissionais enfrentam inúmeras dificuldades ao se depararem com casos de violência contra crianças, em especial quando se trata de abuso sexual. Segundo Furniss (1993), o abuso sexual pode ser considerado como uma "síndrome de segredo" pois, na maioria das vezes, as crianças encontram dificuldades em revelar o que thes aconteceu. Uma das razões para isso é a falta de preparo de quem recebe a denúncia para lidar com o tema. O autor destaca que, nesses casos, é necessário que o profissional tenha capacidade pessoal e profissional para lidar com o assunto, assim como uma estrutura de apoio (serviços, leis, recursos financeiros).

Além disso, também existe o temor, por parte da criança, fato que ocorre como conseqüência de ameaças sofridas pela 
vítima ou porque o agressor é alguém muito próximo. Ainda assim, geralmente, a criança tenta conversar com alguém, seja da própria família, da escola ou outros conhecidos. Entretanto, a reação dessas pessoas, muitas vezes, é de descrédito, julgando que a criança fantasiou o ocorrido; de minimização do dano (sugerindo que "não foi nada" e que deve ser esquecido) ou de responsabilização da vítima, acusando-a de sedutora ou provocadora do abuso (Azevedo \& Guerra, 1998).

Portanto, dificilmente o abuso sexual ou os maus-tratos são a queixa principal das crianças atendidas em consultórios ou serviços médicos. De acordo com Gil, Recondo e Escosteguy (1996), o caso pode chegar aos serviços de saúde a partir de quatro principais maneiras: como uma queixa específica feita pela vítima, familiares ou outras pessoas que se preocupam com a situação (menos freqüente), como causa subjacente de outro problema (os familiares procuram atendimento para os ferimentos, mas inventam alguma desculpa), como um achado ocasional ou por visualização direta do profissional que está atendendo a criança. Assim, todos os profissionais que lidam diretamente com crianças, sejam enfermeiros, médicos, assistentes sociais, professores, cuidadores, etc. devem estar preparados para suspeitar e identificar situações de maus-tratos contra crianças.

\section{Considerações finais}

Como pudemos perceber pelos casos apresentados e pela revisão de literatura, lidar com a problemática da violência contra crianças, em especial o abuso sexual, é uma tarefa bastante árdua, pois envolve não só aspectos emocionais do profissional que está atendendo a criança como também estruturais, tais como o apoio legal, a existência de órgãos e serviços de apoio bem como treinamento para detectar e manejar tais situações. Ainda que no Eca (Brasil, 1990) esteja prevista a obrigatoriedade da notificação até mesmo dos casos de suspeita de maus-tratos contra crianças, isso não é o que ocorre na realidade. No caso específico do profissional que atua em um posto de saúde, geralmente localizado no coração de comunidades carentes e onde o contato com a população é muito próximo, acrescenta-se a dificuldade relativa à exposição que pode acabar sofrendo, levando-o a temer represálias ou ameaças por parte do agressor. A alternativa encontrada por muitas instituições, principalmente hospitais, é a criação de comitês interdisciplinares. Dessa forma, além de haver maior compreensão do caso, propiciada pela colaboração dos profissionais de diversas áreas, a responsabilidade pela denúncia ao Conselho Tutelar não fica personificada apenas em um profissional (geralmente psicóloga ou assistente social), preservando as integridades individuais.

Assim, a sensibilização de profissionais que atuem diretamente com crianças para o tema da violência doméstica e do abuso sexual é de fundamental importância para que estes possam ser abordados e tratados corretamente. Para isso, é importante estender a discussão para toda a comunidade, nas escolas e demais instituições de atendimento a crianças e adolescentes. 


\section{Mariana Porto Ruwer de Azambuja}

Psicóloga graduada pela Pontifícia Universidade Católica do Rio Grande do Sul em 2001/2; Mestre em Psicologia Social e da Personalidade pela PUCRS (órgão financiador CNPq).

Ex-aluna da Residência Integrada em Saúde, da Escola de Saúde Pública do Rio Grande do Sul, no Centro de Saúde-Escola Murialdo ênfase em Atenção Básica em Saúde Coletiva.

Doutoranda em Psicologia Social na Universidade do Minho, Braga,

Portugal (com o apoio do Programa Alban - Programa de Bolsas de Alto Nível da União Européia para a América Latina, no da bolsa EO5DO53211BR)",

World Spru - Residência Universitária, quarto 110 Largo da Estação de Caminhos de Ferro, n/c 4700-223 - Braga - Portugal Fones: (51) 967139 11/30 222415 E-mail:mariruwer@ig.com.br

AZEVEDO, M.A.; GUERRA, V.N. de A. Pele de Asno não É só História: um Estudo sobre Vitimização Sexual de Crianças e Adolescentes em Famílias. São Paulo: Roca, 1998.

BRASIL. Lei Federal n. 8.069, de 13 de julho de 1990. Estatuto da Criança e do Adolescente, 1990.

FURNISS, T. Abuso Sexual da Criança: uma Abordagem Multidisciplinar. Manejo, Terapia e Intervenção Legal Integrados. Porto Alegre: Artes Médicas, 1993.

GOMES, R. Da Denúncia à Impunidade: um Estudo sobre a Morbi-mortalidade de Crianças Vítimas de Violência. Cadernos de Saúde Pública, v. 14. n.2. Rio de Janeiro. Abr./jun.,1998.

GONÇALVES, H. S.; FERREIRA, A. L.; MARQUES, M. J.V. Avaliação de Serviço de Atenção a Crianças Vítimas de Violência. Revista de Saúde Pública, v. 33, n.6. São Paulo, dez., 1999.

GONÇALVES, H. S.; FERREIRA, A. L. A Notificação da Violência Intrafamiliar contra Crianças e Adolescentes por Profissionais de Saúde. Cadernos de Saúde Pública, v. 18, n.1. Rio de Janeiro, jan./fev., 2002.

MINAYO, M. C. de S.; SOUZA, E. R. de . Violência e Saúde como um Campo Interdisciplinar e de Ação Coletiva. História,
Ciências, Saúde. Manguinhos, IV(3), 1998, pp.513-531. Disponível em: <http://www.fiocruz.br/hscience/vol4n3/ art_cecilia.html>

MINAYO, M. C. de S . Violência contra Crianças e Adolescentes: Questão Social, Questão de Saúde. Revista Brasileira de Saúde Materno-Infantil. Pernambuco, v.1, n.2, 2001, pp. 91-102.

NJAINE, K. et al. A Produção da (des)Informação sobre Violência: Análise de uma Prática Discriminatória. Cadernos de Saúde Pública, v. 13, n.3. Rio de Janeiro, jul/set.,1997.

Santana-Tavira, R.; Sánchez-Ahedo, R.; Herrera-Basto, E. El Maltrato Infantil: un Problema Mundial. Salud Pública, v. 40, n.1. México, Cuernavaca, jan/fev. 1998.

VOGEL, A. Do Estado ao Estatuto. In Pilotti e Rizzini (org.). A Arte de Governar Crianças: a História das Políticas Sociais, da Legislação e da Assistência à Infância no Brasil. Rio de Janeiro: Instituto Interamericano del Niño/Editora Universitária Santa Ursula/AMAIS Livraria e Editora, 1995.
Referências 